\title{
Brief Report: A Comparison of the Diagnostic Criteria for Asperger Syndrome
}

\author{
Mohammad Ghaziuddin, ${ }^{1}$ Luke Y. Tsai, and Neera Ghaziuddin
} University of Michigan, Ann Arbor

Asperger syndrome (AS) was first described under the title of autistic psychopathy by the Austrian physician Hans Asperger (1944). Despite the growing interest in it, its nosological status remains uncertain. It is not clear to what extent it differs from autism, although some authorities have proposed that it is part of the "autistic continuum" (Wing, 1981). The DSMIII-R (American Psychiatric Association [APA], 1987) has no separate category for this disorder, and the DSM-IV has not yet decided whether or not to include it (APA, DSM-IV Options Book, 1991). However, the ICD-10 (World Health Organization [WHO], 1988) has included it as a distinct category within the pervasive developmental disorders, because it does not "fulfill the usual criteria for autism and because it remains uncertain whether or not the syndrome is truly synonymous with autism" (Rutter, 1989, p. 504). According to the ICD-10, AS is characterized by a qualitative impairment of reciprocal social interaction; a lack of clinically significant general delay in language or cognitive development; and restricted patterns of behavior and interests. In addition, the disorder is not attributable to the other varieties of pervasive developmental disorder (WHO, 1988).

Most publications have not used any operational criteria for the diagnosis of AS while others have introduced substantial changes to the clinical features described by Asperger. For example, Asperger believed that the patients he described were of normal intelligence. However, some authors have since described patients of Asperger syndrome with mental

\footnotetext{
${ }^{1}$ Address all correspondence to Mohammad Ghaziuddin, Division of Child Psychiatry, University of Michigan Hospitals, 1500 East Medical Center Drive, Ann Arbor, Michigan 48109-0390.
} 
Table 1. Comparison of the Clinical Features of Asperger Syndrome

\begin{tabular}{|c|c|c|c|c|c|c|}
\hline & $\begin{array}{l}\text { Asperger } \\
\text { (1944) }\end{array}$ & $\begin{array}{l}\text { Wing } \\
(1981)\end{array}$ & $\begin{array}{c}\text { Gillberg } \\
(1989)\end{array}$ & $\begin{array}{c}\text { Szatmari } \\
\text { et al. } \\
\text { (1989) }\end{array}$ & $\begin{array}{c}\text { Tantam } \\
\text { (1988) }\end{array}$ & $\begin{array}{c}\text { ICD-10 } \\
(1988)\end{array}$ \\
\hline Speech delay & No & $\begin{array}{l}\text { May be } \\
\text { present }\end{array}$ & $\begin{array}{l}\text { May be } \\
\text { present }\end{array}$ & Not stated & $\begin{array}{l}\text { May be } \\
\text { present }\end{array}$ & No \\
\hline Cognitive delay & No & $\begin{array}{l}\text { May be } \\
\text { present }\end{array}$ & $\begin{array}{l}\text { May be } \\
\text { present }\end{array}$ & Not stated & $\begin{array}{l}\text { May be } \\
\text { present }\end{array}$ & No \\
\hline $\begin{array}{l}\text { Autistic social } \\
\text { impairment }\end{array}$ & Yes & Yes & Yes & Yes & Yes & Yes \\
\hline Clumsiness & Yes & Yes & Yes & $\begin{array}{l}\text { Clumsy } \\
\text { gestures }\end{array}$ & Yes & Usual \\
\hline Pedantic speech & Yes & Yes & Yes & Yes & Yes & $\begin{array}{l}\text { No } \\
\text { mention }\end{array}$ \\
\hline $\begin{array}{l}\text { All absorbing } \\
\text { interests }\end{array}$ & Yes & Yes & Yes & Yes & Yes & Usual \\
\hline
\end{tabular}

retardation (Carpenter \& Morris, 1990; Wing, 1981). Also, Asperger syndrome has been described in patients with and without speech delay (Wing, 1981), although in the original description, patients had no history of speech delay (Asperger, 1944). At least five sets of clinical features or criteria have been used for the diagnosis of this syndrome (Table I). These are those of Asperger himself; and those of Wing (1981), Gillberg and Gillberg (1989), Tantam (1988), and Szatmari, Bremner, and Nagy (1989). The purpose of this paper is to assess to what extent the ICD-10 criteria differ from those of others.

\section{METHOD}

The study was conducted at the Developmental Disorders Clinic of the University of Michigan Hospital. Diagnosis of DSM-III-R Pervasive Developmental Disorder (APA, 1987) was reached after a comprehensive evaluation. This included mental status examination of the patient, semistructured interviews with parents and informants, psychological testing, occupational testing, and speech and language evaluation. Clumsiness was assessed on the basis of history and the observation of the evaluating team. From this group of patients, those meeting Wing's criteria for Asperger syndrome, abstracted from her description of the syndrome (1981), were identified. These patients were then examined on the basis of the clinical features described by Asperger (1944); and the criteria proposed by Gillberg and Gillberg (1989), Szatmari et al. (1989), Tantam (1988), and the ICD-10 (WHO, 1988). 
Table II. Patients With Asperger Syndrome as Defined by Various Diagnostic Criteria/Features ${ }^{a}$

\begin{tabular}{cccccccc}
\hline $\begin{array}{c}\text { Age in } \\
\text { years }\end{array}$ & Sex & $\begin{array}{c}\text { Asperger } \\
(1944)\end{array}$ & $\begin{array}{c}\text { Wing } \\
(1981)\end{array}$ & $\begin{array}{c}\text { Gillberg } \\
(1989)\end{array}$ & $\begin{array}{c}\text { Tantam } \\
(1988)\end{array}$ & $\begin{array}{c}\text { Szatmari } \\
\text { et al. } \\
(1988)\end{array}$ & $\begin{array}{c}\text { ICD-10 } \\
(1988)\end{array}$ \\
\hline 10 & M & - & + & + & + & + & - \\
10 & M & - & + & + & + & - & - \\
10 & M & - & + & + & + & + & - \\
11 & F & + & + & + & + & + & + \\
16 & M & + & + & + & + & + & + \\
16 & F & - & + & + & + & - & - \\
16 & M & + & + & + & + & + & + \\
17 & M & + & + & + & + & + & + \\
18 & M & - & + & + & + & + & - \\
19 & F & + & + & + & + & + & + \\
20 & M & + & + & + & + & + & + \\
21 & M & - & + & + ?clumsy & + & - & - \\
24 & M & + & + & + & + & + & + \\
26 & M & - & + & + & + & + & - \\
52 & M & + & + & + ?clumsy & + & + & + \\
\hline
\end{tabular}

${ }^{a}+$ meets criteria; - does not meet criteria.

\section{RESULTS}

Over a 21 -month period, 128 patients were referred to the clinic. Of these, 82 met the DSM-III-R criteria for autistic disorder and 27 for Pervasive Developmental Disorder Not Otherwise Specified (PDDNOS); 4 patients had a primary diagnosis of mental retardation, 5 presented with superimposed Axis 1 disorders in the setting of mental retardation but without PDDNOS, 2 had a primary communication disorder, and the remaining 8 had a variety of diagnoses such as attention deficit hyperactivity disorder, dysthymia, seizure disorder, and so forth. Fifteen patients met Wing's (1981) description of Asperger syndrome; 6 of these met the criteria for autistic disorder and the remaining 9 for PDDNOS. There were 12 males and 3 females with an age range of 10 to 52 years. Most of the patients were between 10 and 26 years; and only 1 patient was 52 years old.

All the 15 patients who met Wing's description of AS also met the criteria of Gillberg and of Tantam, although in 2 patients, the presence of clumsiness was doubtful. Ten patients met the criteria proposed by Szatmari et al., and only 8 patients met the description of Asperger and of the ICD-10. Thus, about half of the patients diagnosed as suffering from Asperger syndrome by Wing's description were not diagnosed as such using Asperger's description or the ICD-10 criteria. This is shown in Table II. 


\section{DISCUSSION}

The purpose of the study is not to speculate on the diagnostic validity of Asperger syndrome or comment on its differentiation from other disorders, such as high-functioning autism. Rather, it is to point out that what is meant by Asperger syndrome differs from one investigator to another, thereby making the interpretation of research findings difficult. In the present study, eight patients met all the diagnostic criteria. About half of the patients diagnosed as suffering from AS by Wing's description did not meet the ICD-10 criteria. This suggests that the ICD criteria are the most restrictive and stringent. Gillberg's criteria are similar to the features described by Wing except that the former specify the number of criteria required for diagnosis. Criteria used by Gillberg and Gillberg (1989) and those of Tantam are almost similar. This is not surprising since both are derived from Wing's description. Tantam (1988) stated

Rather than overextend the concept of AS, it is best to reserve it as a descriptive label for autistic children who use language freely but fail to make adjustment to fit different social contexts or the needs of different listeners; wish to be sociable but fail to make relationships with peers; are conspicuously clumsy; develop idiosyncratic but engrossing interests; and have marked impairment of non-verbal expressiveness which affect tone of voice, facial expression, gesture, gaze and posture.

Szatmari et al.'s (1989) criteria, on the other hand, although derived from Wing's description, are more stringent because they propose the exclusion of those patients who meet the DSM-III-R criteria of autistic disorder.

An important reason why some patients in the present study did not meet the ICD-10 criteria was the history of language development. Three patients who met Wing's description gave a history of language delay as obtained from parents and other sources. None of them showed a tendency to indulge in pedantic or circumstantial speech. In fact, they tended to be somewhat reticent and reserved in their speech. When tested, their speech showed deficits in expressive, receptive as well as pragmatic areas. In one child with an ICD-10 diagnosis of AS, a relatively normal period of early language development was followed by a plateau during which little language acquisition occurred. However, after a few years, the child apparently resumed speaking more freely. This patient, like the others with an ICD-10 diagnosis of $\mathrm{AS}$, showed a tendency to indulge in one-sided conversation, with little regard to the social context or the interest of the listener. Although we characterized this as "pedantic speech," we were unsure if this was really the case, because no generally accepted definition of pedantic speech exists at present. Besides, it is possible that what constitutes pedan- 
tic speech becomes more obvious in later years, thus minimizing its importance as a diagnostic feature in younger children. It is also conceivable that only a subgroup of patients showing autistic social dysfunction with normal intelligence speak in a pedantic manner. At this stage, therefore, there does not seem to be enough evidence to suggest that all patients who present with autistic social impairment in the presence of normal cognitive and language development possess pedantic speech. It is, perhaps, for this reason, that the ICD-10 makes no mention of pedantic speech as a diagnostic feature of Asperger syndrome.

Another reason for the differences in the diagnostic criteria lies in the fact that the ICD-10 excludes patients with mental retardation. Asperger noted that all his patients had superior intelligence but did not give any IQ assessments. Thus, the implication was that his patients did not suffer from mental retardation. Wing, however, proposed that this was not necessarily true. A substantial number of patients in her series were mentally retarded (Wing, 1981). Similarly, Gillberg and Gillberg (1989) included patients with mental retardation in their epidemiological survey of Asperger syndrome in Sweden. The criteria that Szatmari et al. (1989) proposed did not specifically state that patients with mental retardation should be excluded although the authors stated that their criteria "correspond to the DSM-III-R category of PDDNOS, albeit in those with normal IQ." Tantam (1989) also stated that "Asperger's description does seem to apply particularly to the most intelligent autistic people, but is not only applicable to them." His criteria, therefore, do not specifically rule out patients with mental retardation. The ICD-10 criteria, on the other hand, state categorically that there should not have been any clinically significant cognitive delay in the development of the child, thereby excluding persons with mental retardation. But what should be done when the cognitive delay, if present, is not clinically significant? For example, can a diagnosis of AS be made, based on the ICD-10, when the IQ is 60? Also, how should the presence of cognitive delay be assessed? Although a discussion of what constitutes cognitive delay is beyond the scope of this paper, the justification in favor of the ICD criteria seems to lie in the fact that exclusion of mentally retarded individuals, at least of those with a substantial degree of retardation, would facilitate research into the differences, if any, between AS and high-functioning autism. As the distinction of this syndrome from the latter disorder is crucial (Schopler, 1985), it would be helpful if the category of AS is kept as homogeneous as possible, at least insofar as the absence of mental retardation is concerned.

Wing (1981) did not specify the exact number of clinical features needed for the diagnosis, although she stated that it was not necessary for a person to show all the features. Although, she proposed no essential fea- 
tures in her original paper (Wing, 1981), she subsequently commented upon the presence of certain characteristics, such as clumsiness and pedantic speech, which she described as the major features (Burgoine \& Wing, 1983). Tantam (1988) agreed with her and stated that the category of AS should be reserved for those autistic children who show pedantic speech and conspicuous clumsiness. Gillberg (1989) too proposed clumsiness as an essential diagnostic feature based on a study in which all the patients he diagnosed as AS were found to be clumsy. Although it may well be true that AS is usually associated with clumsiness, the fact remains that very few studies of Asperger syndrome have defined and assessed this symptom in a systematic manner (Ghaziuddin, Tsai, \& Ghaziuddin, 1992). Thus, under the circumstances, the decision of the ICD-10 not to include clumsiness as an essential diagnostic feature seems justified.

Another issue is the simultaneous diagnosis of Asperger syndrome and autism. Asperger believed that the condition he described and the one described by Kanner were two totally different disorders, but did not, to our knowledge, comment on whether or not the two diagnoses can be made simultaneously. Although Wing stated that the two conditions lie on a continuum and are only quantitatively different, she allowed for a diagnosis of AS to be made simultaneously in patients with autism (Wing, 1981). The ICD-10, on the other hand, takes a hierarchical approach and does not allow for a diagnosis of AS to be made when the patient meets the criteria for any other PDD. The same is true of the criteria proposed by Szatmari et al. (1989). If AS and autism indeed occur on a continuum, and differ from each other only in the degree of severity, it is not clear what useful purpose is served by giving both diagnoses in the same person.

No diagnostic criteria have made an allowance for age. Almost all the patients reported in the literature are adolescents or adults. It is possible that circumscribed interests and pedantic speech, which often bring these persons to psychiatric attention, do not develop till the child is at least in his adolescence. For example, it would be much more difficult for a child, even if he is born with the innate tendency to develop idiosyncratic interests to the exclusion of other activities, to become an expert, say, on Sub-Saharan Africa at the age of 4 years, than for the same child at the age of 14. It may, therefore, be useful if the variable of age is taken into account if the criteria are revised.

In conclusion, a variety of criteria are in use today for the diagnosis of AS, which makes the interpretation of research findings difficult. Wing's criteria are flexible; they can be applied to patients with both mental retardation and speech delay; and allow for the dual diagnosis of AS and autism. However, by their very flexibility, they are rather loose and overinclusive; and they make the differentiation from high-functioning autism 
difficult. The criteria proposed by Gillberg and Gillberg, Tantam, and Szatmari et al. are all derived from those of Wing and differ marginally from one another. Gillberg and Gillberg's criteria require the presence of all six features. However, they include patients with mental retardation and language delay. Szatmari's criteria describe "the DSM-III-R category of PDDNOS, albeit in those with normal IQ." They specifically exclude patients with autistic disorder but do not clarify if persons with mental retardation or language delay should be excluded. The ICD-10 criteria are closer to the original description by Asperger than any other criteria. They exclude patients with mental retardation, language delay, and those with other types of pervasive developmental disorders. However, they offer no guidelines about the status of those persons with mild mental retardation who may meet all the other criteria and of those in whom the history of language development cannot be confirmed. Despite these problems, and at the risk of being somewhat rigid and narrow, the ICD-10 criteria attempt to create a homogeneous category which may further our understanding of the various subtypes of pervasive developmental disorders.

\section{REFERENCES}

American Psychiatric Association (1987). Diagnostic and statistical manual of mentai disorders (3rd ed., rev.). Washington, DC: Author.

American Psychiatric Association. (1991). DSM-IV options book: Work in progress. Washington, DC: Author.

Asperger, H. (1944). Die "autistischen Psychopathen" im Kindesalter. Archiv fur Psychiatrie und Nervenkrakheiten, 117, 76-136.

Burgoine, E., \& Wing. L. (1983). Identical triplets with Asperger's syndrome. British Journal of Psychiatry, 143, 261-265.

Carpenter, P. K., \& Morris, D. (1990). Association of acrocyanosis with Asperger's syndrome. Journal of Mental Deficiency Research, 34, 87-90.

Gillberg, C. (1989). Asperger syndrome in 23 Swedish children: A clinical study. Developmental Medicine and Child Neurology, 31, 520-531.

Gillberg, C., \& Gilberg, 1. C. (1989). Asperger syndrome: Some epidemiological considerations: A research note. Journal of Child Psychology and Psychiatry, 30, 631-8.

Ghaziuddin, M., Tsai, L., \& Ghaziuddin, N. (1992). A reappraisal of clumsiness as a diagnostic feature of Asperger syndrome. Journal of Autism and Developmental Disorders, 22, 651656.

Rutter, M. (1989). Annotation: Child psychiatric disorders in ICD-10. Joumal of Child Psychology and Psychiatry, 30, 499-513.

Schopler, E. (1985). Convergence of learning disability, higher-level autism, and Asperger's syndrome. Journal of Autism and Developmental Disorders, 15, 359.

Szatmari, P., Bremner, R., \& Nagy, J. (1989). Asperger's syndrome: A review of clinical features. Canadian Journal of Psychiatry, 34, 554-560.

Tantam, D. (1988). Asperger's syndrome. Journal of Child Psychology and Psychiatry, 29, 24555.

Wing, L. (1981). Asperger's syndrome: A clinical account. Psychological Medicine, 11, 115-29.

World Health Organization. (1988). International classification of diseases and disorders (ICD-10, draft version). Geneva: Author. 